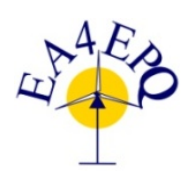

International Conference on Renewable Energies and Power Quality (ICREPQ'15)

La Coruña (Spain), $25^{\text {th }}$ to $27^{\text {th }}$ March, 2015

Renewable Energy and Pourer Quality. Fournal (RE\&PQJ)

ISSN 2172-038 X, No.13, April 2015

\title{
Development of a mobile photovoltaic stand-alone energy supply system
}

\author{
K.K.T. Thanapalan, T.J. Stockley, M.A. Bowkett, J.G. Williams \\ Centre for Automotive \& Power Systems Engineering (CAPSE), Faculty of Computing, Engineering and Science, \\ University of South Wales, Pontypridd CF37 1DL, UK \\ Phone/Fax number: +0044 1443 482542, e-mail: kary.thanapalan@southwales.ac.uk
}

\begin{abstract}
This paper discusses a systematic approach for the design and implementation of a mobile stand-alone photovoltaic (PV) system. The system is designed on the plug and play principle. There are a number of potential system configurations for stand-alone PV system including mobile stand-alone PV system. In remote locations, mobile stand-alone configurations are of interest, and may prove more cost effective than a grid connected systems. In this paper a mobile stand-alone PV system model is developed within the MatLAB/Simulink platform for system analysis and performance optimization. The potential yield of such a mobile stand-alone PV system design is investigated using data collected at an industrial test site and the performance of the PV system under variable conditions determined. This paper also described an optimal design and implementation of an efficient mobile stand-alone PV system. The structure of the PV system and design methodologies is also discussed. Tests were conducted with the implementation of the new design and the results show that the system performance improved significantly.
\end{abstract}

Keywords: Modeling, PV system, controller design.

\section{Introduction}

Solar energy is one of the most promising energy sources for widespread application [1]. The solar system has been deployed widely and more and more organisations and people are benefiting from installing photovoltaic (PV) panels, which converts the solar energy to electrical energy [2]. The reason for that includes its free access and abundance for most of the places in the world. The installation of PV system is growing significantly in response to the increasing global energy demand. It is estimated that the PV industry had a global total of $40 \mathrm{GW}$ capacity which is significant compared with other renewable energy sources [3]. PV system can be operated in two different modes such as stand alone or grid connected [4]. Mobile stand-alone PV system could assist for conserving the environment by using solar energy in locations without access to electricity and act as an indispensable electricity source for remote areas. However, due to its intermittency and fluctuation, one of the important research challenges is to improve the system's efficiency and performance.
The effort to increase the amount of solar energy usage is important to a number of different of sectors; especially in the area of i) housing and buildings in countryside, ii) tourism in rural areas and iii) farming industry. All these three sectors consume a significant amount of primary energy for thermal or electrical power. However, these sectors have practical difficulties in forming a strong electrical power grid connection, because of legal requirement for minimum energy etc. An alternative approach is to look at the potential use of the stand-alone PV system. In recent years, the importance of mobile stand-alone PV system has been recognized globally; see for example [5], [6], and [7]. Furthermore, in particular, these three sectors are very important to Wales's economy and its sustainability due to its geographical place in the world. Wales is home to many historical sites which are spread throughout the countryside. Implementing electronic information displays in museums and much of the more popular historical sites may prove to be problematic, as power cables will disturb the landscape and prove costly. By using a solar powered information board such as that produced by Nexus Alpha, and being installed by ScotRail [8], information can be delivered to visitors at sites in even the most remote places. Much of Wales is reliant on tourism, with its many caravan and camping sites attracting holiday makers throughout the spring and summer months. Figures from the Welsh Government [9] show that in 2011, £328 million was spent by visitors to Wales. Two methods have been identified to further aid the tourism industry; i) For people staying in campsites while on holiday, accessing a power source for charging of devices such as mobile phones, torches and cameras could prove difficult. Implementing a solar panel/array standalone power point in campsites would allow the campers to have access to charge such devices. This service would also provide a new revenue source for campsite operators, as visitors would be charged for this utility. ii) a common problem occurring with caravans that are placed on a caravan site, but are only used for small sections of the year is that they are prone to damp. This problem occurs as a result of escalating condensation and a lack of air circulation throughout the unused caravan. By using a solar panel with integrated lithium cells, the user can power a dehumidifier or heating system to remove the condensation and therefore prevent damp. 
As with the rest of the UK, farming forms a vital part of the industrial sector. The weather provides a stern test for many farmers throughout the year, especially in recent years where winters have become very unpredictable. Two products have been identified to be incorporated with the solar panel and battery module to protect livestock in the harsh conditions; i) solar powered barn heating/cooling systems will allow the storage barn to be kept warm through the winter and cool through the summer. This will allow protection of storage supplies or livestock. ii) during the periods of heavy snow or drought, livestock struggle to graze on the land. Recent reports [10] suggested that livestock deaths in March 2013 were as a result of the snow, as it proved too difficult for farmers to deliver food for the sheep in such hazardous conditions. These cases could be reduced by the use of a solar powered food distribution system supplying fresh food to the animals at practical intervals.

The structure of the paper is as follows. We first provide a mobile stand-alone PV system modeling and system analysis, followed by a description of the mobile standalone PV system development, in which we discuss the temperature effects on each subsystem within the common architecture.

\section{System modeling}

The common mobile stand-alone PV system architecture will have the following subsystems, which are, PV modules, battery pack, converters, controllers and tasks. For illustration purpose a block diagram of a typical mobile stand-alone PV system is shown in Figure 1.

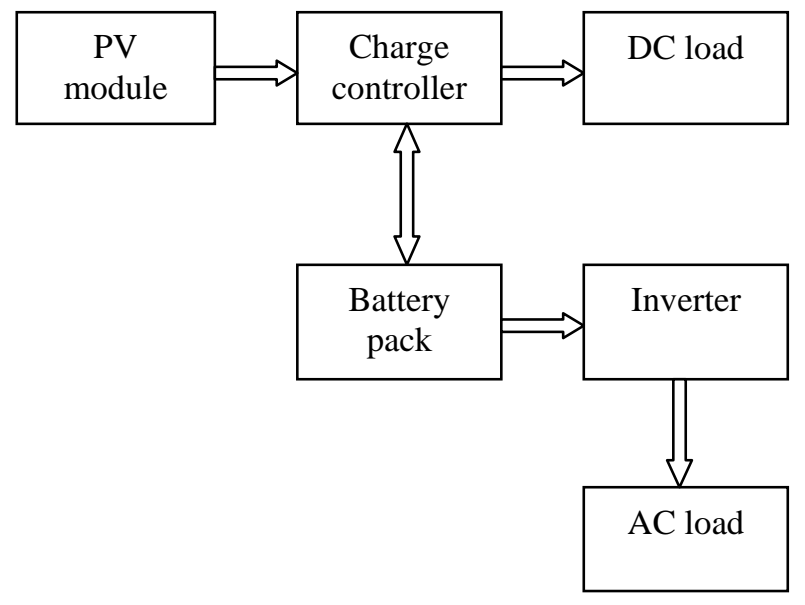

Figure 1. Block diagram of a mobile stand-alone PV system

\section{A. PV system}

Several researchers have addressed the development of an accurate PV model, and the design and application of such systems [1] - [7], [11], [12] and [13]. In this paper, a common but accurate PV model presented in [11] is adopted. The advantage of this model is that it will give an accurate calculation of the output power/current based on the given light density and cell temperature; furthermore, all the parameters in this model may be obtained from manufacturers' data sheet. Photovoltaic (PV) arrays have been widely used around the world as a powerful device to convert solar energy to electricity. Most modern PV cells use a semiconductor p-n junction to absorbed light energy. A single cell is wired in series/parallel combination to form a module in order to achieve certain voltage/current levels. An array is an interconnection of numerous modules. The model of the PV system is based on an equivalent circuit which consists of a current source, a diode and a series resister as shown in Figure 2.

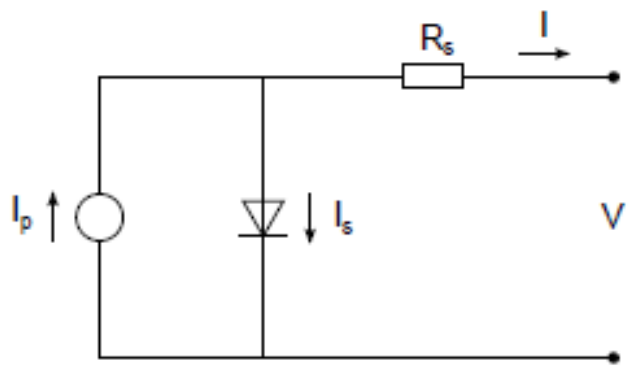

Figure 2: Equivalent circuit of the PV system

The typical current-voltage (I-V) characteristic of a solar cell is expressed as [11]:

$$
I=I_{p}-I_{s}\left(\exp ^{\left(V+I R_{S} / \varepsilon V_{t}\right)}-1\right)
$$

where $I_{p}$ is the photo current, $I_{s}$ is the reverse saturation current which is affected by the temperature of the PV cell, $V$ is the voltage applied on the diode, $\mathcal{E}$ is the ideality factor, which normally varies from 1 to 2 depending on the diode itself and in many cases it is assumed to be approximately equal to $1 . V_{t}$ is the thermal voltage $V_{t}={ }^{k_{B} T} / q$ with the Boltzmann constant $k_{B}=1.38 \times 10^{-23} J K^{-1}, T$ is the absolute temperature of the diode in Kelvin, and $q=1.6 \times$ $10^{-19} \mathrm{C}$ is the charge of the electron. Finally, $R_{S}$ is the equivalent series resistance of the PV array describing an internal resistance to the current flow. The photo current generated by the light depends linearly on the irradiation of the sun and it is also influenced by the temperature of the cell:

$$
\begin{aligned}
& I_{p=} I_{p r}+K_{0}\left(T-T_{r}\right) \\
& I_{p r}=I_{s c r} \frac{E}{E_{r}}
\end{aligned}
$$

where $E$ is irradiation, $I_{p}$ is photo current, $T$ is the cell temperature, while the subscript $r$ represents reference, $K_{0}$ is the temperature coefficient of short circuit current $I_{s c}$ which can be found from the manufacturer's data sheet together with $T_{r}, E_{r}$ and $I_{s c r}$. 
The reverse saturation current can be calculated from following equations,

$$
\begin{aligned}
& I_{s}=I_{s r}\left(\frac{T}{T_{r}}\right)^{\frac{3}{\varepsilon}} \exp \left(-\frac{q V_{g}}{\varepsilon k_{B}}\left(\frac{1}{T}-\frac{1}{T_{r}}\right)\right) \\
& I_{s r}=\frac{I_{s c r}}{\exp \left(\frac{q V_{o c_{r}}}{\varepsilon k_{B} T_{r}}\right)-1}
\end{aligned}
$$

where $\mathrm{Vg}$ is the band gap voltage.

The series resistance can be determined by

$$
\begin{gathered}
R_{s}=-\frac{d V}{d I_{V_{o c}}}-\frac{1}{X_{V}} \\
X_{V}=I_{s r} \frac{q}{\varepsilon k_{B} T_{r}} \exp \left(\frac{q V_{o c_{r}}}{\varepsilon k_{B} T_{r}}\right)
\end{gathered}
$$

where $\frac{d V}{d I_{V_{o c}}}$ can be generated from manufacturers graph.

\section{B. Battery system}

The second energy source is the battery system. Several models are presented in the literature for predicting the battery behavior; see for example [14], [15] and [16]. These models differ in functionally and complexity. Therefore, the choice of model is dependent on the requirement of the application. Furthermore, battery management system (BMS) is an integral part of any battery hybrid system, which ensures that the battery system is functioning within the specified safe operating conditions [17]. Thus, it is important to note that the incorporation of a BMS is essential to the safe and efficient operation of the battery system.

\section{a) Battery model}

The battery pack effectively creates a DC-link between all components in the mobile stand-alone PV system. Its functionalities include as an energy store and buffers fluctuations in storage and compensate for fluctuation in power generation by the PV cells. Thus, charge and discharge characteristic description model is required for this application. A battery model [18], [19] is based on its charge and discharge characteristic can be expressed as;

$$
\begin{aligned}
V_{b}^{d}=E_{0} & -R \cdot i_{b}-K \cdot \frac{Q}{Q-i_{b} t} \cdot\left(i_{b} t+i_{b}^{*}\right) \\
& +A \exp \left(-B \cdot i_{b} t\right) \\
V_{b}^{c}=E_{0} & -R \cdot i_{b}-K \cdot \frac{Q}{i_{b} t-0.1 \cdot Q} \cdot i_{b}^{*}-K \frac{Q}{Q-i_{b} t} \\
& +A \exp \left(-B \cdot i_{b} t\right)
\end{aligned}
$$

where, $V_{b}^{d}$ and $V_{b}^{c}$ are battery voltage at the discharge and charge mode respectively. $E_{0}$ is battery constant voltage, $R$ is internal resistance, $Q$ is battery capacity, $i_{b}^{*}$ is filtered current and $i_{b} t$ is actual battery charge. $A$ and $B$ are exponential zone amplitude and time constant inverse respectively.

The battery current $i_{b}$ is defined by

$$
i_{b}=-\left(i_{P V}-i_{L}\right)
$$

where $i_{P V}$ and $i_{L}$ are $\mathrm{PV}$ modules current and the load current respectively.

\section{b) BMS design}

Mobile stand-alone PV systems require new approaches to over-come usability restraints. One of the solutions is to design and implement an optimal battery management system (BMS). By doing so, it will increase the reliability of the entire system. Battery management system (see Figure 3) is an important subsystem for mobile stand-alone PV system, which ensures that the batteries are operating within the specified safe operating conditions. Thus, the design of battery management system plays an important role on the battery life preserving and performance improvement of the mobile stand-alone PV system.

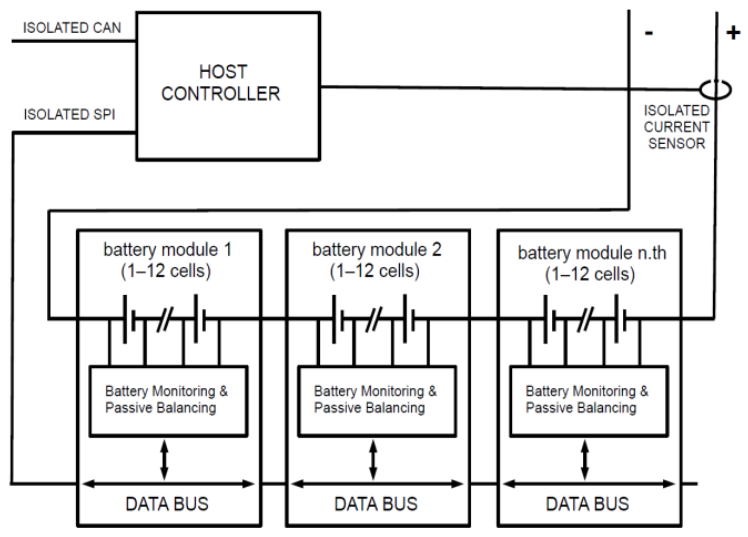

Figure 3. A simple BMS system [20]

\section{Convertors and Invertors}

The convertors/ invertors considered in this paper should have the ability to convert high voltage into low voltage. Therefore, a buck DC/DC converter is chosen to drive a low voltage battery pack from a higher voltage solar panel and a maximum power point tracking (MPPT) controller is needed to be developed in order to adjust the duty cycle of the converter [13]. This allows for optimal performance of the system by generating maximum solar power.

\section{Controller design}

In general the mobile stand-alone PV system has the advantage of using a simple system configuration and simple control scheme [6], [7]. However, the energy conversion efficiency of a PV module is very low and to 
overcome this problem and to get the maximum possible efficiency, the design of all the elements of the PV system has to be considered and optimized. The PV system possess strong non-linear characteristics and there is a single operating point which is called the maximum power point (MPP) that provides the maximum power under certain light density and cell temperature conditions [11], [13] and [21]. There is a probable mismatch between the load current and voltage characteristics and the MPP. Therefore, tracking the MPP is essential to improve the system efficiency and performance optimization. Recent research efforts show that several different control methods for the maximum power point tracking (MPPT) of a PV system under variable temperature and isolation conditions has been investigated, see for example [11], [13], [22], [23] and [24]. There are many ways of distinguishing and grouping the control methods that seek the MPP from a PV system. However, essentially and in general terms there are two approaches to MPPT; direct and indirect methods [5]. The direct MPPT method presented in [11] is adopted in this paper.

The parameters for the system models are obtained from the manufacturer's data sheets. The solar module provides maximum power $P_{\max }$ of about $70 \mathrm{~W}$. Voltage and current at $P_{\max }$ are $18.4 \mathrm{~V}$ and $3.75 \mathrm{~A}$ respectively. The short circuit current $I_{s c}$ is $4.1 \mathrm{~A}$ and open circuit voltage $V_{o c}$ is $22 \mathrm{~V}$. The $I-V$ characteristic for the PV panel with different cell temperature can be generated from the above system model and they are demonstrated in Figure 4 with the $x$-axis and yaxis representing the voltage and current respectively.

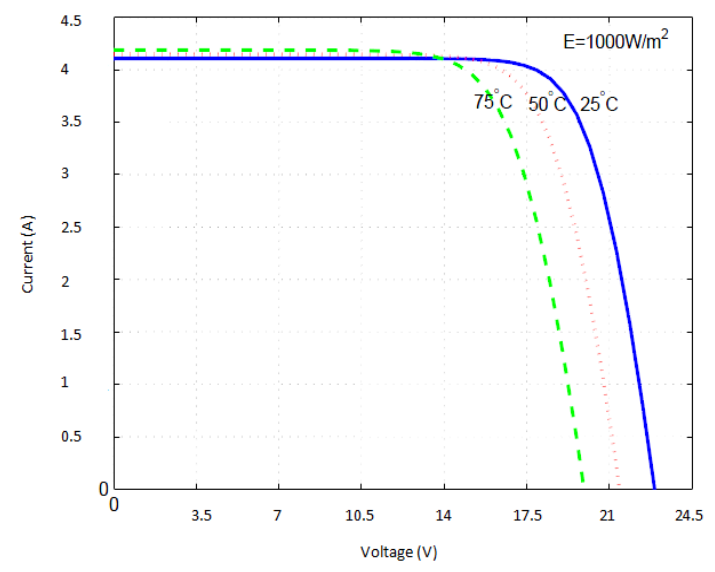

Figure 4. $I-V$ characteristic for the PV panel with different cell temperature

Power obtained from the PV module for a specific day has been shown in Figure 5. From Figure 5 it can be observed that during typical peak daylight about 50 65 $W$ power can be obtained.

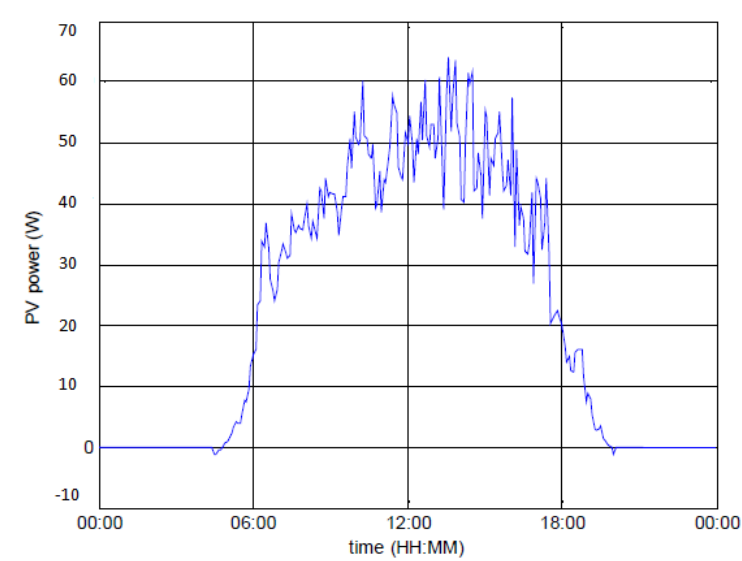

Figure 5. PV power against time (24hrs)

The analysis presented above has been applied to investigate the effect of temperature on a real mobile standalone PV system. The remaining sections of the paper describe the experimental study and implementation of an optimal mobile stand-alone PV system.

\section{Experimental study}

The mobile stand-alone PV system studied in this paper is the PV-battery hybrid system. The PV system consists of a $70 \mathrm{~W}$ PV module, a four pack $40 \mathrm{Ah}$ Li-Ion battery pack with nominal voltage of $3.7 \mathrm{~V}$ each, a buck DC/DC converter and a controller. The controller incorporated in this particular system is the Morningstar's SunSaver MPPT $^{\mathrm{TM}}$ solar controller with TrakStar ${ }^{\mathrm{TM}}$ Technology; it is an advanced maximum power point tracking (MPPT) battery charger for off-grid PV systems. The entire system was tested in various conditions to verify its performance while experimental data was collected from the PV system components.

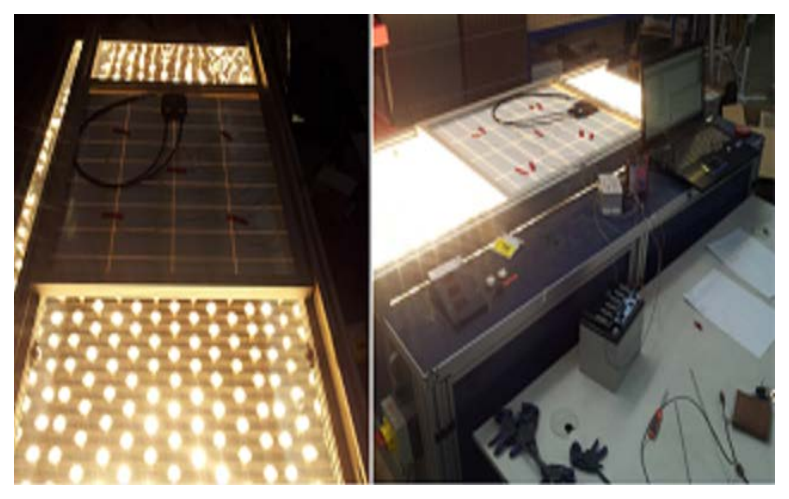

Figure 6. Laboratory setup of the PV system

To conduct system monitoring analysis, performance assessment and demonstrate the mobile stand-alone PV system concept, researchers at the Faculty of Engineering, 
Computing and Science in the University of South Wales used a laboratory setup, which is illustrated by Figure 6 and 7. Figure 6 shows the general laboratory setup of the PV system and Figure 7 shows the PV system testing in the laboratory condition, in that the PV module is glide over a test-bed with $1000 \mathrm{Wm}^{-2}$ which represents an average mid-day sun light acting perpendicular to the cells of the PV panel.

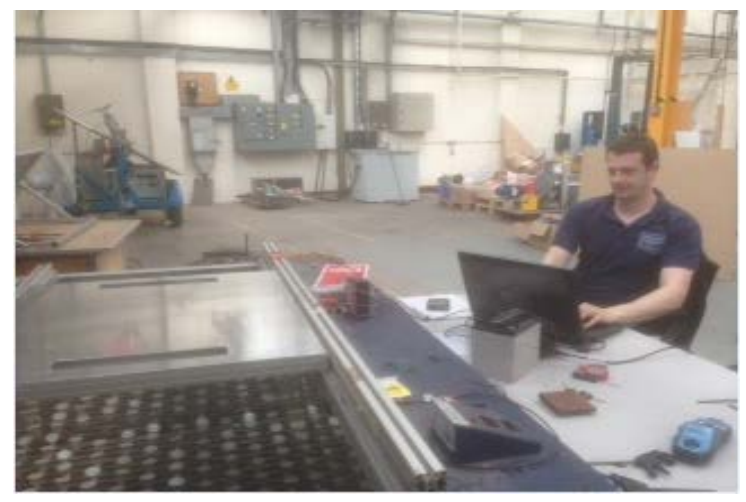

Figure 7. Testing of a PV module

System monitoring can provide useful information about their operation and what should be done to improve performance. It is important to monitor the performance of individual components in order to refine and improve system performance. However, each component may have several parameters and monitoring all of them is a very difficult task indeed. Thus, key performance parameters need to be identified and selected in order to monitor system behavior and performance optimization. For this system temperature is identified as an important parameter to monitor for performance improvement and optimal system design.

Now consider the temperature of the energy sources, i.e., the battery pack and PV module. The battery pack used in this system is the four pack $40 \mathrm{Ah} \mathrm{Li}$-ion battery with nominal voltage of $3.7 \mathrm{~V}$. Its operational temperature range has been testified and verified in the centre for automotive and power systems engineering at the University of South Wales. It has been observed that the storage range is $-30^{\circ} \mathrm{C}<T<60^{\circ} \mathrm{C}$, whereas, the charge temperature range is $0^{\circ} \mathrm{C}<T<45^{\circ} \mathrm{C}$ and the discharge temperature range is $-30^{\circ} \mathrm{C}<T<60^{\circ} \mathrm{C}$ which is the same as the standard operational range specified by the manufacture. For the PV module, in order to analyse temperature effects of the system, several different tests were conducted with varying test conditions. Results for a typical case are presented in this paper as an example (see Figure 8).

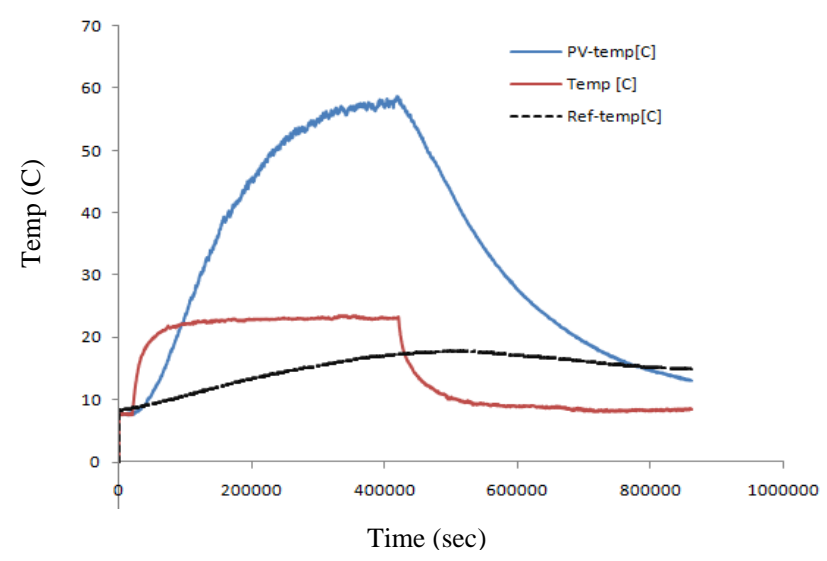

Figure 8. Temperature characteristic for PV system

For this test, temperature sensors were mounded on the back of the PV module to measure the PV cell temperature (PVtemp), out-side of the PV test-bed (blue surface) to measure the reference ambient temperature (Ref-temp) and just above the test-bed in front of the PV module to measure the system temperature with heat irradiation (Temp), see Figures 6 and 8. It has been observed that the temperature on the back of the PV panel is evenly distributed and in general, many repeated tests it was found below $70^{\circ} \mathrm{C}$. However some worse case scenarios were tested with tight mounting of the back cover without any air-gaps and the test results show that the temperature can reach above $70^{\circ} \mathrm{C}$. Therefore it is essential that an optimal design of back cover fitting is incorporated in the system design. Through this testing and system analysis we have designed an optimal back cover fitting for the PV module. Thus, further tests were conducted with the implementation of our new design and the results were significantly improved. Therefore, it is possible that an efficient mobile stand-alone PV system can be implemented with the use of Li-ion battery that has a storage range of temperature $-30^{\circ} \mathrm{C}<T<60^{\circ} \mathrm{C}$.

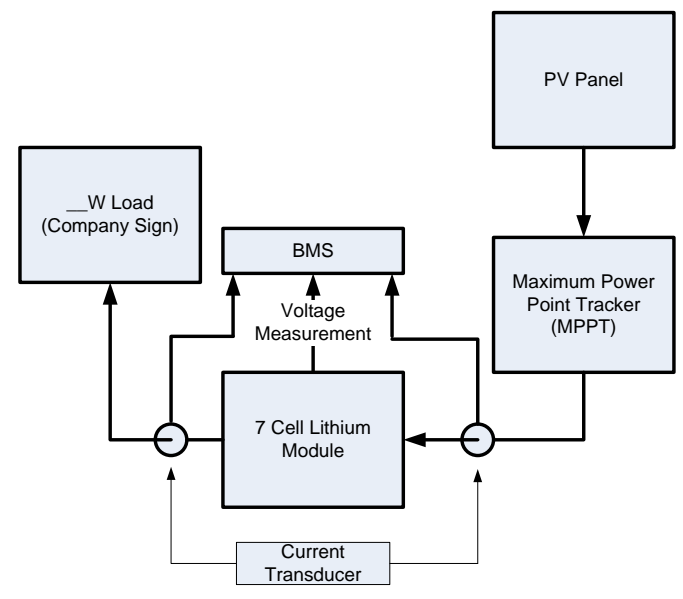

Figure 9. Mobile stand-alone PV system application [24] 
Applying the analysis and design methodologies, a simple but an efficient mobile stand-alone PV system has been designed (see Figure 9). The system is able to power up a $12 \mathrm{~V}$ DC lamp which may be used to light up the sign board in the night or other electrical equipments such as TV, fan and radio etc.

\section{Conclusion}

The paper describes the modeling, simulation and experimental study of a mobile stand-alone PV system. A mathematical model for a PV system has been developed for simulation study and system analysis. This paper also described an optimal design and implementation of an efficient mobile stand-alone PV system. The structure of the PV system and design methodologies is also discussed. Tests were conducted with the implementation of the new design and the results show that the system performance improved significantly. This study leads to the design of an optimal mobile stand-alone PV system. Analysis of the system results shows performance enhancements compared to the existing typical design of a mobile stand-alone PV system.

\section{References}

[1] T. Esram, P. L. Chapman, 'Comparison of Photovoltaic Array Maximum Power Point Tracking Techniques', IEEE Transactions on Energy Conversion, vol. 22, no. 2, pp. 439-449, 2007.

[2] M. A. S. Masoum, H. Dehbonei, E. F. Fuchs, 'Theoretical and experimental analyses of photovoltaic systems with voltage and current-based maximum power-point tracking', IEEE Transactions on Energy Conversion, vol. 17, no. 4, pp. 514-522, 2002.

[3] K. Thanapalan, F. Zhang, S. Carr, G. Premier, A. Guwy, J. Maddy, 'An overview of renewable energy technologies and hydrogen economy' Renewable Energy and Power Quality Journal, vol. 1, no. 11, pp. 322:1-6, March. 2013

[4] N. H. A. Rahman, A. M. Omar, 'Modeling of a maximum power point tracker for a stand-alone photovoltaic system using MATLAB/Simulink', Int. J. Low-Carbon Tech., pp. 1-7, Oct. 2012.

[5] V. Salas, E. Olías, A. Barrado, A. Lázaro, 'Review of the maximum power point tracking algorithms for stand-alone photovoltaic systems', Solar Energy Materials and Solar Cells, vol. 90, no. 11, pp. 1555-1578, Jul. 2006. Energy Storage in photovoltaic stand-alone energy

[6] G. Bopp, H. Gabler, K. Preiser, D. U. Sauer, H. Schmidt, 'Energy storage in photovoltaic stand-alone energy supply systems', Progress in Photovoltaics: Research and Applications, vol. 6, no. 4, pp. 271291, 1998.

[7] J.P. Dunlop, 'Batteries and charge control in stand-alone photovoltaic systems'. Fundamentals and Application, Sandia National Laboratories, 1997.

[8] ScotRail website on solar powerd screens be installed in highland stations, [online, 2013], Avilable: //www.scotrail.co.uk/content/solarpowered-screens-be-installed-highland-stations
[9] Welsh Government website on tourism in wales, [online, 2014], Availabe:http://wales.gov.uk/topics/tourism/researchl1/tourisminwale s/?lang=en

[10] Guardin website on cold spring kills newborn lambs, [online, 2014], Available:http://www.guardian.co.uk/uk/2013/mar/26/cold-springkills-newborn-lambs

[11] F. Zhang, K. Thanapalan, J. Maddy, A. Guwy, 'Development of a novel hybrid maximum power point tracking methodology for photovoltaic systems', in 18th International Conference on Automation and Computing (ICAC), pp. 1-6, 2012

[12] T. Noguchi, S. Togashi, R. Nakamoto, 'Short-current pulse-based maximum-power-point tracking method for multiple photovoltaicand-converter module system', IEEE Transactions on Industrial Electronics, vol. 49, no. 1, pp. 217-223, 2002.

[13] F. Zhang, K. Thanapalan, A. Procter, S. Carr, J. Maddy, G. Premier, 'Power management control for off-grid solar hydrogen production and utilisation system', International Journal of Hydrogen Energy, vol. 38, no. 11, pp. 4334-4341, Apr. 2013.

[14] S. Barsali, M. Ceraolo. 'Dynamical models of lead-acid batteries: implementation issues', IEEE Transaction on Energy Conversion vol 17, no. 1, pp.16-23, 2002.

[15] C. Min, G. A. Rincon-Mora, 'Accurate electrical battery model capable of predicting runtime and I-V performance', IEEE Transactions on Energy Conversion 21 (2):504- 511, 2006

[16] B. Schweighofer, K. M. Raab, G. Brasseur, 'Modeling of high power automotive batteries by the use of an automated test system', IEEE Transactions on Instrumentation and Measurement 52 (4):1087-1091, 2003

[17] X. Zhang, P. Liu, D. Wang, 'The Design and Implementation of Smart Battery Management System Balance Technology', Journal of Convergence Information Technology, Vol. 6, No. 5, pp. 108-116, May 2011

[18] K. Thanapalan, J. Williams, G. Premier, A. Guwy, 'Design and implementation of renewable hydrogen fuel cell vehicles', Renewable Energy and Power Quality Journal, vol. 9, no. 310, p. 1-6, 2011.

[19] O. Tremblay, L. A. Dessaint, 'Experimental validation of a battery dynamic model for EV applications', World Electric Vehicle Journal, vol.3, pp.1-10, 2009

[20] M. Bowkett, K. Thanapalan, T. Stockley, M. Hathway, J. Williams, 'Design and implementation of an optimal battery management system for hybrid electric vehicles'. in 19th International Conference on Automation and Computing (ICAC), pp. 213-217, 2013

[21] G. Walker, 'Evaluating MPPT converter topologies using a MATLAB PV model', Journal of Electrical \& Electronics Engineering, Australia vol. 21, no. 1, pp. 49-55, 2001.

[22] A. Al-Amoudi, L. Zhang, 'Optimal control of a grid-connected pv system for maximum power point tracking and unity power factor', in Seventh International Conference on (Conf. Publ. No. 456), Power Electronics and Variable Speed Drives, 1998, pp. 80-85, 1998.

[23] C. Hua, J. Lin, 'Fully digital control of distributed photovoltaic power systems', Industrial Electronics, Vol. 1, pp. 1-6, 2001.

[24] T. Stockley, K. Thanapalan, M. Bowkett, J. Williams, 'Design and implementation of OCV prediction mechanism for PV-Li-ion battery system', in 20th International Conference on Automation and Computing (ICAC), pp. 49-54, 2014 